Case Report

\title{
SAUVE - KAPANDJI PROCEDURE FOR M ALUNITED DISTAL RADIUS FRACTURE: A CASE REPORT
}

\author{
Sanath Kumar Shetty ${ }^{1}$ Joseph John ${ }^{2}$, Lawrence John Mathias ${ }^{3} \&$ H Ravindranath Rai ${ }^{4}$ \\ ${ }^{1}$ Assistant Professor, ${ }^{2}$ Postgraduate, ${ }^{3}$ Professor, Professor and Head ${ }^{4}$, Department of Orthopaedic Surgery, \\ K.S. Hegde Medical Academy, Nitte University, Deralakatte, M angalore, Karnataka, India. \\ Correspondence \\ Sanath Kumar Shetty \\ Assistant Professor, Department of Orthopaedic Surgery, K.S. Hegde M edical Academy, \\ Nitte University, Deralakatte, Mangalore - 575 018, Karnataka, India. \\ Mobile : +91 9845069383 E-mail : sanathkumarshetty@ hotmail.com
}

\begin{abstract}
:
Distal radioulnar joint disorders are a frequent cause of wrist pain and instability. The etiology include displaced fractures or malunions of the distal radius and tears of the triangular fibrocartilage complex with DRUJ instability.

A 47 year old gentleman presented to us with complaints of pain and deformity of the right wrist of one and half years duration. Radiographs revealed a malunited distal radius fracture.

He underwent Sauve Kapandji procedure. Follow ups were done at periodic intervals and wrist physiotherapy was instituted. He had acceptable wrist motion at six weeks.
\end{abstract}

Keywords: Sauve Kapandjii, distal radius, malunion

\section{Introduction:}

Arthrodesis of the distal radioulnar joint combined with the creation of a pseudarthrosis of the distal ulna is referred to asthe Sauvé Kapandji procedure ${ }^{1}$.

Arthrodesis of the DRUJ, with creation of the distal ulnar pseudarthrosis, maintained the ulnar head in a good position, provided support for the ulnar carpus, and allowed prono-supination at the pseudarthrosis ${ }^{1}$.

The Sauvé-Kapandji procedure is indicated for treatment of conditions that result in DRUJ pain or instability or both and that are refractory to nonsurgical treatment ${ }^{1}$.

It is contraindicated when there is insufficient or absent bone stock of the distal ulna, when there is an unstable interosseous ligament of the forearm combined with the

\begin{tabular}{|c|}
\hline Access this article online \\
\hline Quick Response Code \\
\hline
\end{tabular}
absence of the radial head, or when there is active infection or other soft tissue problems at the proposed surgical site. ${ }^{1}$

Case Report: :

A 47 year old gentleman presented with complaints of pain,deformity and restricted movement of right wrist of one and half years duration.

Clinical examination revealed shortened radius with manus valgus deformity. Range of motion in all directions was $5^{\circ}$. His pre operative wrist score was 40 which is indicative of poor inference.

Radiographs revealed malunited distal radius fracture with subluxation of the distal radio ulnar joint (Figure 1).

He underwent arthrodesis of the DRUJ, with creation of the distal ulnar pseudarthrosis (Sauve-Kapandji procedure). His post operative radiographs showed a satisfactory fixation (Figure 2). He was followed up regularly. One month following surgery he was started on physiotherapy and was assessed periodically. At the end of 6 months he had acceptable range of painless range of motion at the wrist with dorsiflexion of $70^{\circ}$, palmar flexion $60^{\circ}$, supination of $80^{\circ}$ and pronation of $60^{\circ}$ with a Mayo wrist score of 80 , which is infers a good result (Figures $3,4,5$ ). 


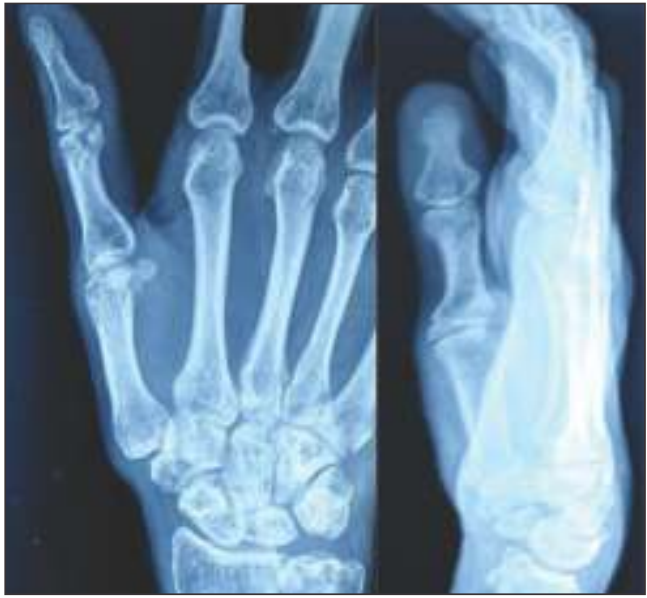

Figure 1 : AP and lateral pre operative radiographs

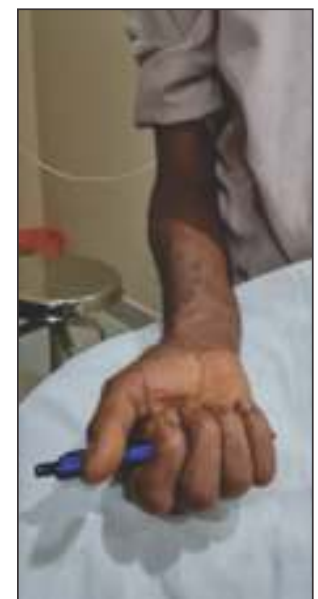

Figure 4 : Clinical picture showing supination of $80^{\circ}$

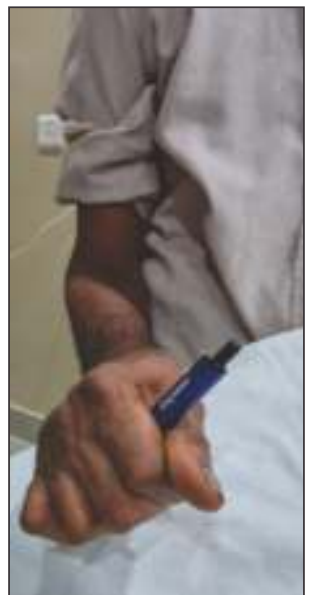

Figure 5 : Clinical picture showing pronation of $60^{\circ}$

\section{Discussion :}

The Sauvé-Kapandji procedure has been recommended as a treatment for DRUJ derangement because unlike the Darrach procedure the ulnar head at the wrist is preserved. Although satisfactory clinical outcomes have been reported after the Sauvé-Kapandji procedure, postoperative instability of the proximal ulnar stump or radioulnar convergence may occur, as with the Darrach procedure ${ }^{1 .}$ Lamey and Fernandez ${ }^{2}$ reported that patients with preoperative instability, subluxation, or dislocation of the DRUJ were more likely to have postoperative problems with instability of the proximal ulnar stump.

Taleisnik ${ }^{3}$ suggested that in cases involving subluxation or dislocation of the DRUJ, rupture of the interosseous membrane, which had contributed to static stability, could

\section{Figure 2 : AP and lateral post} operative radiographs

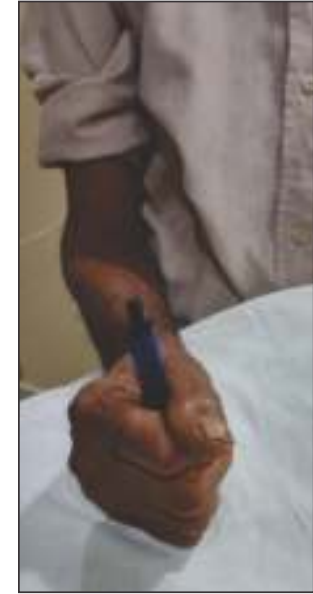

Figure 3 : Clinical picture showing neutral wrist position

result in an excessively mobile distal ulna even after surgery. Because chronic derangement in most patients noting discomfort at the proximal ulnar stump was caused by DRUJ dislocation, Kapandji ${ }^{4}$ suggested that leaving a short distal ulna fragment, fashioning the ulnar gap as far distally as possible, and creating a pseudarthrosis of approximately $10 \mathrm{~mm}$ would decrease the instability of the proximal ulnar stump. To obtain more stability of an excessively mobile proximal ulnar stump, Kapandji's4 recommendation should be followed combined with the tenodesis procedure, especially when the cause of DRUJ derangement is dislocation.

In our case, we performed arthrodesis of distal radioulnar joint with creation of pseudo arthrodesis of the distal ulna. We however, did not perform any tenodesis. Our patient had good wrist function.

\section{References:}

1. Hironobu Inagaki, MD, Ryogo Nakamura, MD, Emiko Horii, MD, Etsuhiro Nakao, MD, Masahiro Tatebe, MD. Symptoms and Radiographic Findings in the Proximal and Distal UInar Stumps after the Sauvé-Kapandji Procedure for Treatment of Chronic Derangement of the Distal Radioulnar Joint. The Journal of Hand Surgery. Volume 31, Issue 5, M ay 2006, Pages 780-784.

2. D.M. Lamey, D.L. Fernandez. Result of the modified Sauvé-Kapandji procedure in the treatment of chronic posttraumatic derangement of the distal radioulnar joint. J Bone Joint Surg, 80A (1998), pp. 1758-1769.

3. J. Taleisnik. The Sauvé-Kapandji procedure. Clin Orthop, 275 (1992), pp. 110-123.

4. I.A. Kapandji. Opération de Kapandji-Sauvé. Techniques et indications dans les affections non rhumatismales. [The Kapandji-Sauvé operation. Its techniques and indications in non rheumatoid diseases]. Ann Chir Main, 5 (1986), pp. 181-193 